\title{
ARTICLE Caspase-mediated cleavage of raptor participates in the inactivation of mTORC1 during cell death
}

\author{
R Martin ${ }^{1}, \mathrm{CDesponds}^{1}$, RO Eren ${ }^{1}, \mathrm{M}$ Quadroni $^{1,2}, \mathrm{M} \mathrm{Thome}^{1}$ and N Fasel ${ }^{1}$
}

The mammalian target of rapamycin complex 1 (mTORC1) is a highly conserved protein complex regulating key pathways in cell growth. Hyperactivation of mTORC1 is implicated in numerous cancers, thus making it a potential broad-spectrum chemotherapeutic target. Here, we characterized how mTORC1 responds to cell death induced by various anticancer drugs such rapamycin, etoposide, cisplatin, curcumin, staurosporine and Fas ligand. All treatments induced cleavage in the mTORC1 component, raptor, resulting in decreased raptor-mTOR interaction and subsequent inhibition of the mTORC1-mediated phosphorylation of downstream substrates (S6K and 4E-BP1). The cleavage was primarily mediated by caspase- 6 and occurred at two sites. Mutagenesis at one of these sites, conferred resistance to cell death, indicating that raptor cleavage is important in chemotherapeutic apoptosis.

Cell Death Discovery (2016) 2, 16024; doi:10.1038/cddiscovery.2016.24; published online 18 April 2016

\section{INTRODUCTION}

The mammalian target of rapamycin (mTOR) is an evolutionary conserved protein complex positively regulating anabolic pathways (protein synthesis, energy metabolism, cell survival and cytoskeletal organization) but also repressing catabolic pathways (autophagy and apoptosis). Two different mTOR complexes exist: ${ }^{1,2}$ mTOR complex 1 (mTORC1) and mTOR complex 2 (mTORC2). These two complexes are both composed of the mTOR serine/threonine protein kinase, deptor, ${ }^{3} \mathrm{mLST}^{4}$ and tti1/ tel2. ${ }^{5}$ In addition, mTORC1 is composed of specific proteins: the regulatory-associated protein of mTOR (raptor) ${ }^{6}$ and pras $40,{ }^{7}$ whereas $\mathrm{mTORC2}$-specific proteins are the rapamycin-insensitive companion of mTOR (rictor), ${ }^{8,9} \mathrm{mSin} 1^{10}$ and protor 1 and $2 .^{11}$

Raptor acts as a scaffold protein inside mTORC1, maintaining the dimerization state of the complex ${ }^{12-14}$ and recruiting substrates to the kinase domain of mTOR. ${ }^{15}$ In this context, the initiation of the protein translation machinery is controlled at two different levels by raptor and mTOR. On one hand, raptor binds and recruits the eukaryotic translation initiation factor 4E-binding protein 1 (4E-BP1) to $\mathrm{mTORC1}$, allowing its phosphorylation by mTOR at Thr37/46, which induces the release of 4E-BP1 from the eukaryotic translation initiation factor $4 \mathrm{E}$ (elF4E) and gives rise to the activation of cap-dependent mRNA translation. ${ }^{16,17}$ On the other hand, raptor binds to the p70 S6 kinase 1 (p70 S6K1) enabling its phosphorylation by mTOR at Thr389, which induces p70 S6K1 to phosphorylate the S6 ribosomal protein and activate protein synthesis. ${ }^{18,19}$

As a central regulator of cell growth, mTORC1 is frequently hyperactivated in a large proportion of human cancers, ${ }^{20}$ leading to tumorigenesis. This is mainly due to mutations occurring in upstream regulators of mTORC1 (such as RTK, PI-3K, Akt, Erk, PTEN and $\mathrm{p} 53),{ }^{1}$ giving rise to hyperactive $\operatorname{mTORC} 1$, increase in phosphorylation of its downstream targets and thus, enabling abnormal proliferation. In addition, activating mutations have been identified in the MTOR gene, leading to hyperactivation of the mTOR pathway. ${ }^{21}$

In this context, the mammalian target of rapamycin has been largely studied as a target for cancer treatments. Inhibitors of mTOR like rapamycin (an allosteric inhibitor) and its analogs (rapalogs) were developed to target this complex. However, the presence of negative feedback loops in the mTOR pathway may have a role in the limitation of treatment efficacy of rapalogs. ${ }^{22-27}$

To counteract this effect, inhibitors of the mTOR kinase activity were developed and unlike rapamycin, a more robust repression of $4 \mathrm{E}-\mathrm{BP} 1$ phosphorylation was reached with the use of these inhibitors. ${ }^{24,26}$ Recently, new strategies have been developed to target $\mathrm{mTORC} 1$ and its upstream regulators at the same time in order to block the oncogenic cascade. Promising results were obtained using dual PI-3K/mTOR inhibitors. ${ }^{23}$

Common chemotherapies against various types of cancer are using etoposide and cisplatin to induce cancer cell apoptosis. ${ }^{28,29}$ Cisplatin is a platinium-based drug creating DNA crosslinking and triggering apoptosis, whereas etoposide is a topoisomerase inhibitor causing DNA strand breaks and promoting apoptosis. These two drugs are also known to affect the mTOR pathway by reducing phosphorylations of $4 \mathrm{E}-\mathrm{BP} 1$ and $\mathrm{S} 6 \mathrm{~K}^{30-32}$

Natural compounds are now emerging as alternative therapies for cancer treatments such as curcumin, the polyphenol compound extracted from rhizome of the plant Curcuma longa. This compound has been shown to alter proliferation of cancer cells and also to disrupt the mTORC1 by weakening mTOR-raptor interaction. $^{33-35}$

In an attempt to understand more deeply the molecular mechanisms of anticancer drugs targeting mTORC1, we studied the cell death cascade induced by different drugs on lymphoma cell lines. We report here that rapamycin, cisplatin, etoposide, curcumin, staurosporine (STS) and Fas ligand (FasL) induced

\footnotetext{
${ }^{1}$ Department of Biochemistry, University of Lausanne, Vaud, Switzerland and ${ }^{2}$ Protein Analysis Facility (PAF), Centre Intégratif de Génomique, Quartier UNIL-Sorge, University of Lausanne, Lausanne, Switzerland. 
caspase-mediated cleavage of raptor and inactivation of the mTORC1, a critical step for apoptosis induction.

\section{RESULTS}

Raptor is cleaved in various drug-treated lymphoma cell lines To investigate the effect of anticancer drugs on mTORC1, we incubated lymphoma cell lines with cisplatin or etoposide. As shown in Figure $1 a$, treatment of $B$ lymphoma cell lines (BJAB and
SUDHL4) for $15 \mathrm{~h}$ with cisplatin induced a cleavage of the fulllength raptor protein of $150 \mathrm{kDa}$ into a smaller fragment of approximately $100 \mathrm{kDa}$. Similar observations were made after $15 \mathrm{~h}$ of etoposide treatment in T (Hut78) and B (BJAB) cell lymphomas (Figure 1b).

The regulatory-associated protein of mTOR (raptor) is composed of three evolutionarily conserved domains: a raptor N-terminal (N-term) conserved domain (also called RNC), three HEAT repeats and seven WD repeats, which are protein interaction domains mediating the raptor-mTOR interaction. ${ }^{14}$ This interaction has

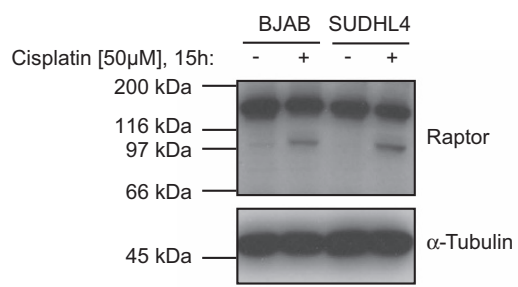

c
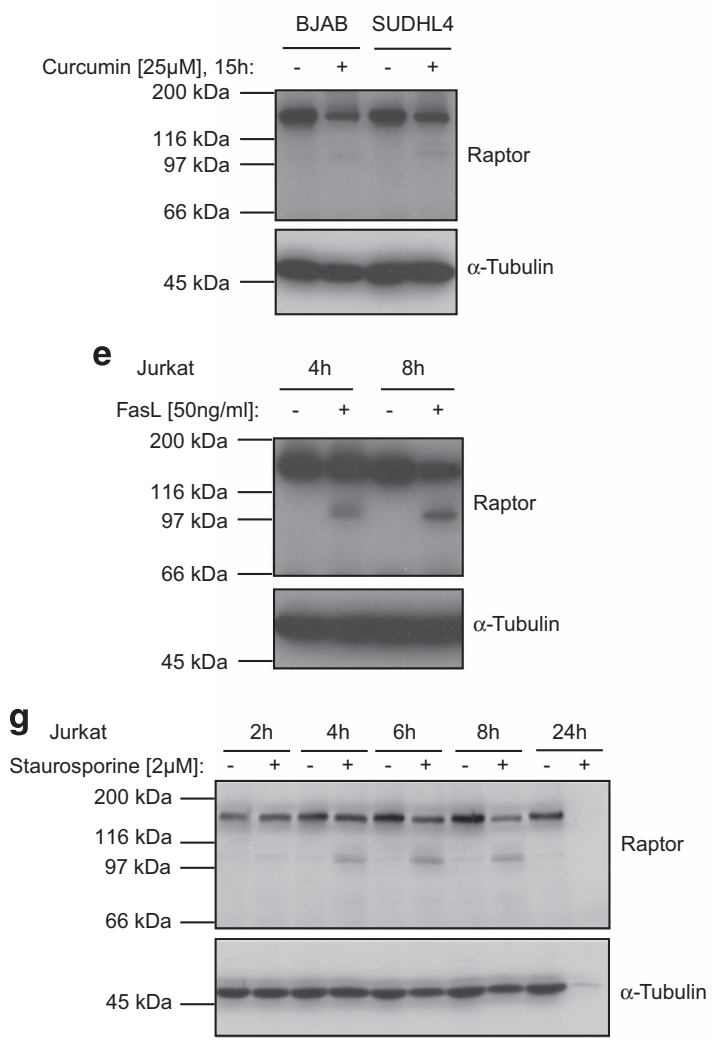

i Raptor mAb

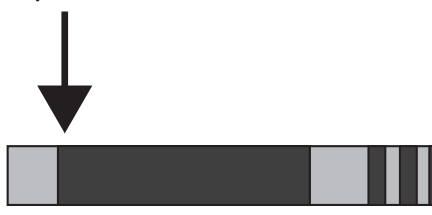

RNC

h b

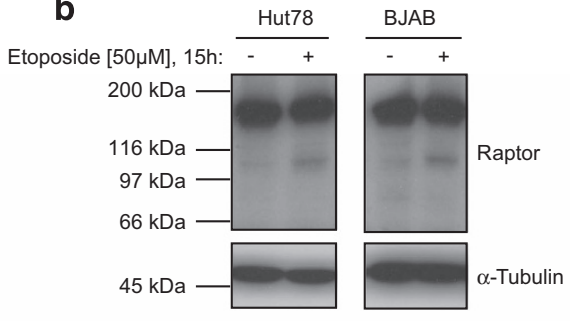

d

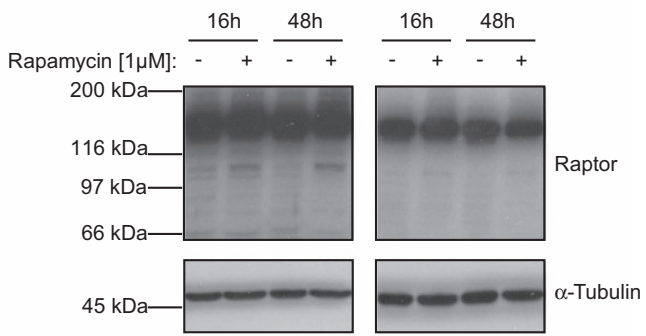

f Hut78

FasL $[50 \mathrm{ng} / \mathrm{ml}]: \frac{4 \mathrm{~h}}{-+} \frac{8 \mathrm{~h}}{-+}$
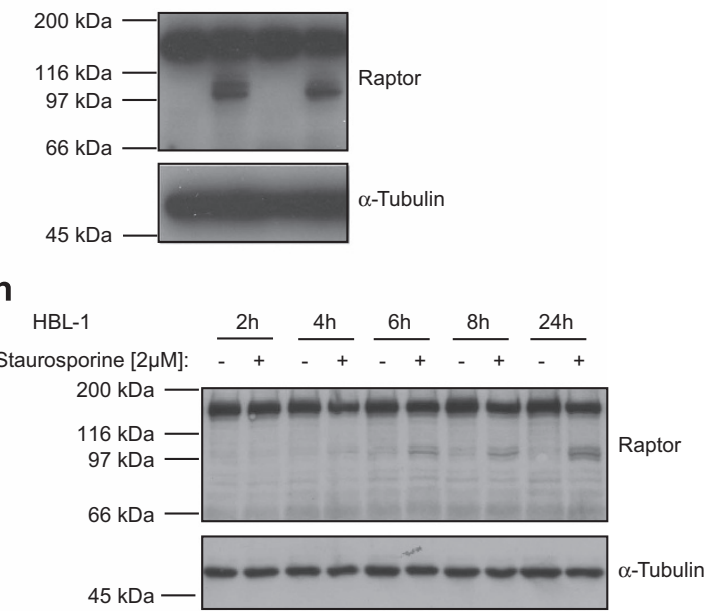

Putative cleavage site

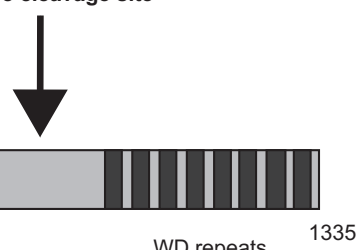

Figure 1. Raptor cleavage upon drug treatment in various T lymphoma and B-cell lines. Lymphoma $\mathrm{T}$ (Jurkat, Hut78) or B-cell lines (HBL-1, $\mathrm{BJAB}$, SUDHL4) were incubated with $50 \mu \mathrm{M}$ of cisplatin for $15 \mathrm{~h} \mathrm{(a),} 50 \mu \mathrm{M}$ of etoposide for $15 \mathrm{~h}$ (b), $25 \mu \mathrm{M}$ of curcumin for $15 \mathrm{~h}$ (c), $1 \mu \mathrm{M}$ of rapamycin for 16 or $48 \mathrm{~h}(\mathbf{d}), 50 \mathrm{ng} / \mathrm{ml}$ of FasL for 4 or $8 \mathrm{~h}$ (e and $\mathbf{f}$ ) and with $2 \mu \mathrm{M}$ of STS for 2, 4, 6, 8 or $24 \mathrm{~h}$ (g and $\mathbf{h})$. Cell lysates were then analyzed on $8 \%$ SDS-PAGE. (i) Scheme of raptor protein highlighted with the region recognized by the raptor mAb and with the putative cleavage site. RNC, raptor N-term conserved domain; HEAT, Huntingtin, elongation factor 3 (EF3), protein phosphatase 2A (PP2A), and the yeast kinase TOR1; WD, tryptophan-aspartic acid (WD) dipeptide. 


\section{a}

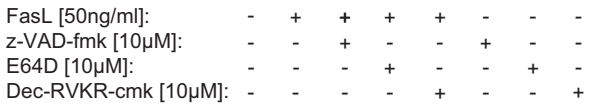

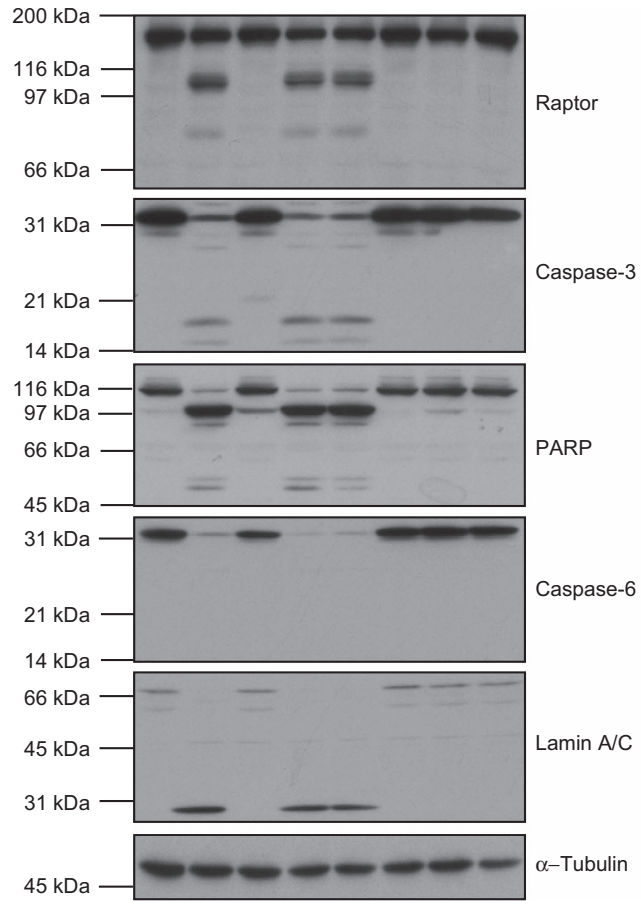

b

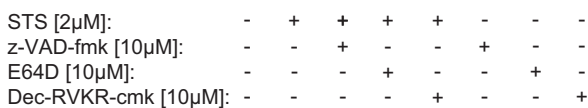

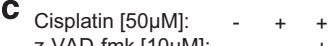

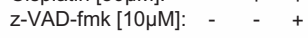

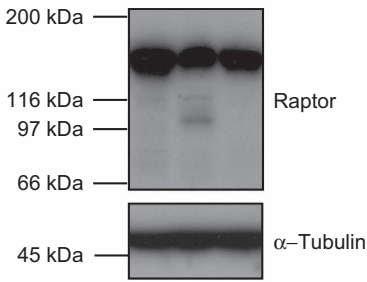

Figure 2. Inhibition of raptor processing by z-VAD-fmk. Jurkat T cells were pre-incubated for 30 min with different inhibitors (z-VAD-fmk, E64D or Dec-RVKR-cmk) and then treated with FasL for $4 \mathrm{~h}(\mathbf{a})$, STS for $4 \mathrm{~h}$ (b) or with cisplatin for $16 \mathrm{~h}$ (c). Cell lysates were then analyzed on $8 \%$ or $12 \%$ SDS-PAGE.

been previously shown to be weakened after curcumin or highdose rapamycin treatments. ${ }^{34,36}$ For this reason, we next investigated the effect of curcumin or rapamycin on lymphoma cell lines. After treatment with curcumin or rapamycin, raptor was also cleaved into a $100 \mathrm{kDa}$ fragment in B lymphoma cell lines (Figures $1 \mathrm{c}$ and $\mathrm{d}$ ), supporting the previously reported destabilizing effect of curcumin and rapamycin on mTORC1. As cisplatin, etoposide, curcumin and rapamycin were reported as apoptosis inducers, ${ }^{33,37-39}$ we decided to use two other well-described cell death inducers, STS and FasL, to assess the correlation between cell death and raptor processing. ${ }^{38,40}$ Treatment of $T$ and $B$ lymphoma cell lines with FasL (Figures 1e and f) or STS (Figures 1g and $\mathrm{h}$ ) both induced a clear processing of raptor into a $100 \mathrm{kDa}$ fragment. Interestingly, we used a rabbit monoclonal antibody (mAb) recognizing the $\mathrm{N}$-term part of raptor, which suggested that, based on the size of cleaved fragment, the observed cleavage occurred within the C-terminal (C-term) part of raptor, probably between the HEAT repeats and the WD repeats (Figure 1i).

Taken together, these data showed that anticancer drug treatments as well as apoptosis inducers gave rise to a cleavage of raptor, an essential scaffold protein of the mTORC1.

Raptor cleavage is mediated by caspases

Different proteases activated during cell death can be responsible for the observed cleavage of raptor. For this reason, we decided to test the following cell permeable protease inhibitors and verify whether they affected raptor cleavage: a general caspase inhibitor (z-VAD-fmk), a cathepsin inhibitor (E64D) and a furin inhibitor (Dec-RVKR-cmk). Jurkat T cells were used as the processing of raptor was easily induced in this cell line. Treatment of Jurkat $\mathrm{T}$ cells for $4 \mathrm{~h}$ with FasL induced a clear cleavage of raptor into the above-described $100 \mathrm{kDa}$ fragment, and with lower efficiency, into an additional, smaller fragment of 70-80 kDa (Figure 2a). The addition of the caspase inhibitor (z-VAD-fmk) completely abolished the cleavage of raptor and well-known apoptotic events, whereas the cathepsin and furin inhibitors had no effect on the processing. In addition, z-VAD-fmk efficiently inhibited raptor cleavage induced by intrinsic apoptosis inducers: STS or cisplatin (Figures $2 b$ and $c$ ).

These results indicated that activation of caspases, by extrinsic or intrinsic apoptosis inducers, mediated raptor processing into molecular species of $100 \mathrm{kDa}$ and $70-80 \mathrm{kDa}$.

\section{Active recombinant caspase- 1 and caspase- 6 can cleave raptor in vitro}

To determine more precisely which caspase(s) could be implicated in raptor cleavage, recombinant caspase(s) $-1,-2,-3,-6,-7,-8$ and -9 were incubated with Jurkat T-cell lysates (Figure 3a). In comparison with cells treated with STS, used a positive control, caspase- 6 was the only caspase that induced processing of raptor into the expected $100 \mathrm{kDa}$ band, whereas caspase- 1 was able to cleave raptor into two smaller fragments of roughly 70 and $80 \mathrm{kDa}$. Although recombinant caspase- 1 and -6 induced an in vitro time-dependant cleavage of raptor in Jurkat T-cell lysates (Figure $3 \mathrm{~b}$ ), activation of the inflammatory caspase- 1 in bone marrow-derived macrophages (BMDMø) did not highlighted processing of raptor, suggesting that caspase-1 most likely did not account for physiological raptor cleavage (Supplementary Figure S1). ${ }^{41}$

As recombinant caspase- 6 generated similar processing of raptor than treatment with pro-apoptotic drugs, we decided to investigate this processing in more detail. In Figure $4 a$, the cleavage of the poly (ADP-ribose) polymerase (PARP) by caspase-3 


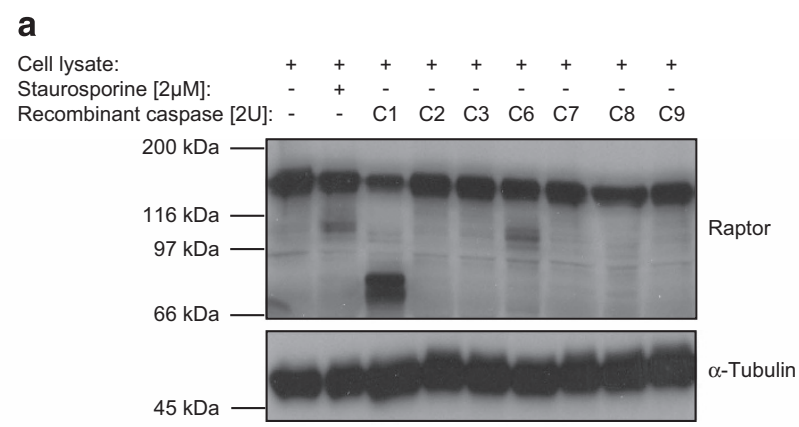

b
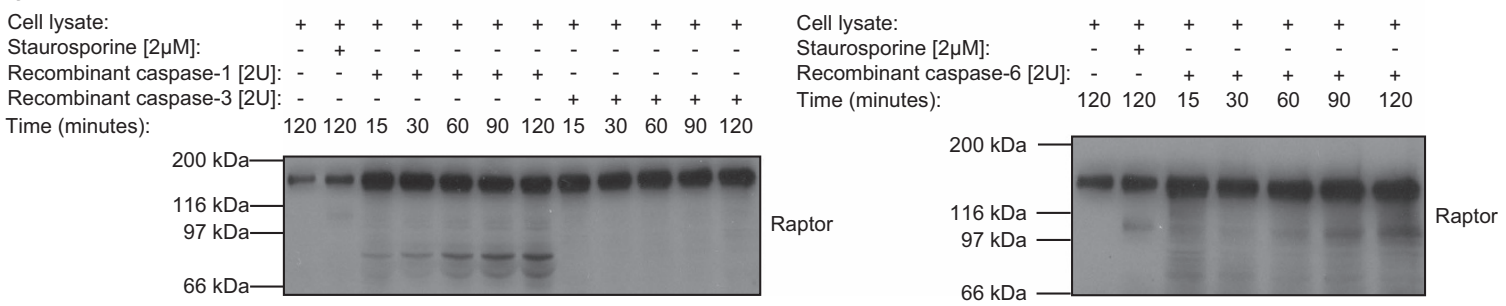

Figure 3. In vitro cleavage of raptor by recombinant caspase-1 and -6. (a) Jurkat T-cell lysates were incubated with two units of recombinant caspase-1 (C1), caspase-2 (C2), caspase-3 (C3), caspase-6 (C6), caspase-7 (C7), caspase-8 (C8) or caspase-9 (C9) and raptor cleavage was monitored and compared with a STS-treated Jurkat T-cell lysate. (b) Time-dependant in vitro cleavage of raptor by caspase-1, -3 or -6 in Jurkat T-cell lysates using two units of each recombinant proteins.

and $-7,{ }^{42}$ and the cleavage of lamin $\mathrm{A} / \mathrm{C}$ by caspase $-6^{43,44}$ revealed the specificity of these active recombinant caspases in Jurkat T-cell lysate. As shown before, caspase- 6 was the only executioner caspase able to cleave raptor in cell lysates and addition of z-VADfmk abolished processing of raptor, confirming that the cleavage was depending on the catalytic activity of recombinant caspase- 6 (Figures $4 a$ and b).

To clarify whether the processing of raptor obtained with recombinant caspases occurred directly or in two steps, as a consequence of activation of another protease in the lysates by these recombinant caspases, we used a recombinant mTORC1 composed of essential proteins required for mTOR activity (Figure 4c). The cleavage of raptor was observed in the presence of caspase- 6 and also with caspase- 3 , yielding a fragment with the same molecular mass $(100 \mathrm{kDa})$ than observed after apoptosis induction. This processing was completely abolished after addition of z-VAD-fmk. Cleavage of full-length raptor $(150 \mathrm{kDa})$ was less strong with caspase-3 when compared with caspase-6, and caspase-7 was not able to cleave recombinant raptor inside the mTORC1 (Figure 4d).

Taken together, these results showed that recombinant caspase- 6 efficiently cleaved raptor in Jurkat T-cell lysates as well as recombinant raptor inside mTORC1. Whereas raptor could not be cleaved in cell lysates by other recombinant caspases such as caspase- 3 and -7 , recombinant caspase- 3 was able to cleave recombinant raptor inside $\mathrm{mTORC1}$, suggesting that different caspases could be implicated in raptor processing.

Caspase- 6 has a role in raptor processing in vivo under apoptotic conditions

To confirm in vivo caspase-6-mediated processing of raptor, we used a caspase- 6 knockout (KO) chronic myelogenous leukemia cell line (KBM-7) generated by gene trapping (Figure 4e). As expected, the cleavage of caspase- 6 and lamin A/C were only observed in WT cells after STS or FasL treatments and not in caspase- 6 KO cells. Raptor processing was clearly reduced (but not completely abolished) in caspase- $6 \mathrm{KO}$ compared with WT KBM-7 cells. This suggests that caspase- 6 has a major role in raptor processing in vivo, but other caspases most likely contribute to this process.

Raptor is cleaved at the C-terminus part after DDADD residues It is known that caspases are exclusively recognizing the negatively charged aspartic acid (or aspartate (Asp, D)) residues in the P1 position of the cleavage site. Two potential cleavage sites, corresponding to the size of the cleaved fragment, were found within the C-term part between the HEAT repeats and the WD repeats: DDADD (UniProtKB: Q8N122, amino acids 939-943) and AVADKD (amino acids 1039-1044) (Figure 5a). To understand if these residues were involved in the caspase-mediated cleavage of raptor, Jurkat T cells were transiently transfected by electroporation with raptor WT or mutated constructs (DDAAA or AVAAKA) (Figures $5 \mathrm{~b}$ and c). Similar expression levels were achieved for the WT, DDAAA and AVA $\underline{A K} \underline{A}$ raptor constructs detected via an HA tag at the N-terminus or via an anti-raptor antibody, which detected both the endogenous raptor polypeptide and the overexpressed raptor constructs. The processing of raptor was sometimes evident already in non-treated cells for the WT construct, possibly as a consequence of the stress induced by the transfection, but it was further increased by STS treatment (Figure $5 \mathrm{~b}$ ). On the other hand, the cleavage of the DDAAA construct was clearly reduced compared with the WT or the AVAAKA raptor constructs, in both treated and untreated cells. A similar decrease in raptor cleavage was observed with the DDAAA versus the WT raptor constructs after FasL treatment (Figure $5 c$ ). Interestingly, after overexpression of raptor WT or mutated constructs in Jurkat $T$ cells, an additional cleavage fragment appeared at approximately $70-80 \mathrm{kDa}$ after cell death induction (Figures $5 \mathrm{~b}$ and $\mathrm{c}$ ). This faster migrating cleaved band could correspond to a lower efficiency caspase-mediated cleavage site.

Taken together, these experiments highlighted the importance of the DDADD, amino-acid 939-943 residues (located within the raptor C-term region, between the HEAT repeats and the WD repeats), in the caspase-mediated processing of raptor. 
a

Cell lysate:

Staurosporine $[2 \mu \mathrm{M}]:-++++$

Recombinant caspase [2U]: $-\quad \begin{array}{lllll}- & - & \text { C3 } & \text { C6 } & \text { C7 }\end{array}$

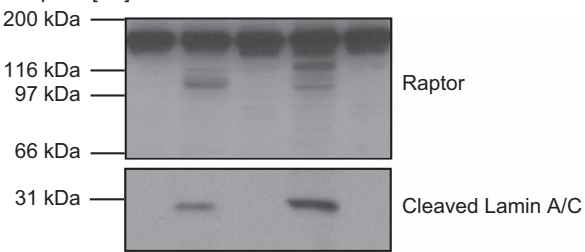

$21 \mathrm{kDa} \longrightarrow$ Cleaved Caspase-6

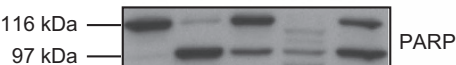

$21 \mathrm{kDa}$

$14 \mathrm{kDa} \longrightarrow$ Cleaved Caspase-3

$21 \mathrm{kDa} \longrightarrow$ Cleaved Caspase-7

$45 \mathrm{kDa} \longrightarrow \alpha-\alpha-$-Tubulin

C
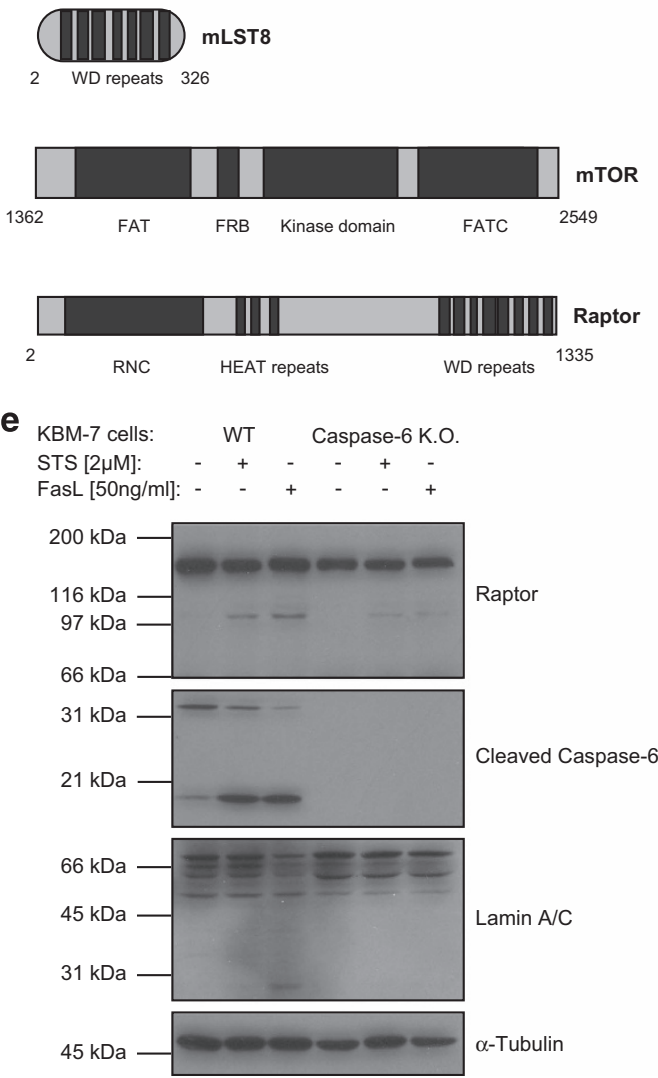

b

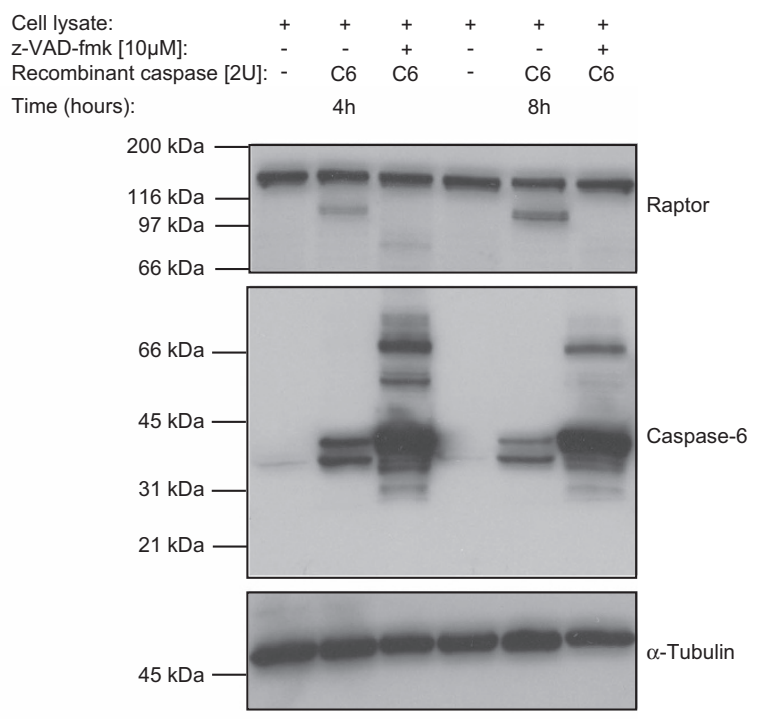

d

$\begin{array}{llllll}\text { Recombinant mTORC1: } & + & + & + & + & + \\ \text { z-VAD-fmk [10 } \mu \mathrm{M}]: & - & - & + & - & -\end{array}$

Recombinant caspase [2U]: - $\quad$ C6 6 C6 $\quad$ C3 $\quad$ C7

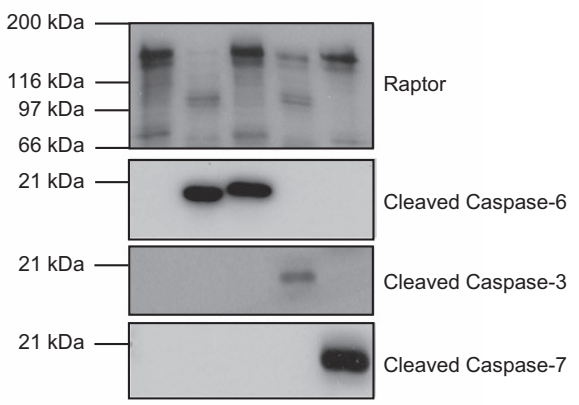

Figure 4. Raptor cleavage by caspase- 6 and other caspases. (a) Jurkat T-cell lysates were incubated with recombinant caspases-3, $-6,-7$ for $2 \mathrm{~h}$. Cleavage of raptor and physiological substrates of caspases (PARP and lamin A/C) were monitored and compared with the positive control sample (Jurkat T cells treated with STS for $2 \mathrm{~h}$ ). (b) The effect of z-VAD-fmk on the recombinant caspase-6-mediated cleavage of raptor in Jurkat T-cell lysate. (c) Cartoon of recombinant mTORC1 (composed of mLST8, mTOR (1362-end) and recombinant raptor). FAT, focal adhesion targeting; FRB, FKBP12-rapamycin binding; FATC, C-term focal adhesion targeting. (d) Cleavage of the full-length recombinant raptor (inside recombinant $\mathrm{mTORC}$ ) by recombinant caspase- $6,-3$ and -7 in the presence (or not) of z-VAD-fmk. (e) WT versus caspase-6 K.O. KBM-7 cells were treated with STS or FasL for $4 \mathrm{~h}$ and then cell lysates were analyzed by SDS-PAGE and western blot.

Raptor is cleaved at the N-terminus part after DEADLTD residues As shown in Figures $5 b$ and $c$, the HA tag signal disappeared after STS or FasL treatment, possibly due to activation of caspases that could cleave inside the HA tag sequence ${ }^{45}$ and/or because of the presence of a raptor $\mathrm{N}$-term cleavage site. To determine the presence of a potential $\mathrm{N}$-term raptor cleavage site, we used a recombinant glutathione-S-transferase (GST)-raptor protein. This recombinant protein has a molecular mass of $70 \mathrm{kDa}$ and contains 
a

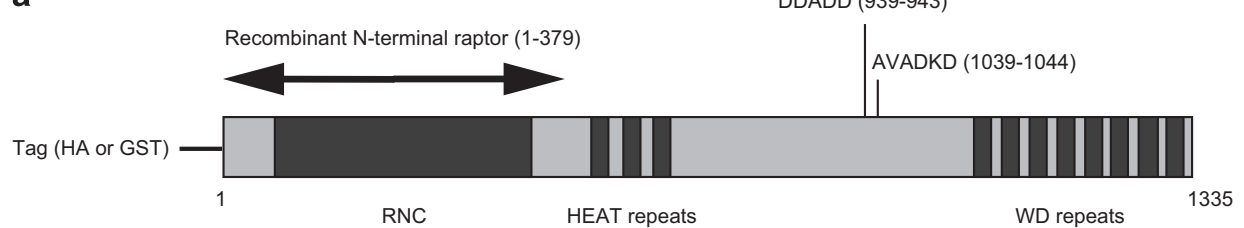

b

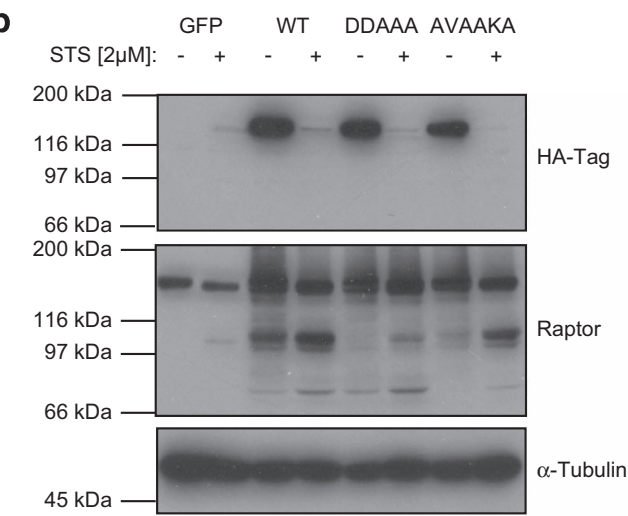

C $\quad$ GFP WT DDAAA

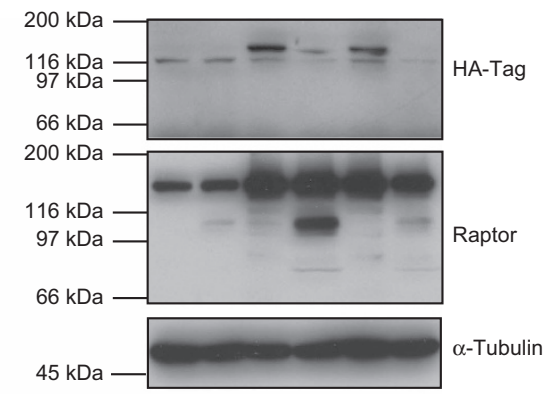

d

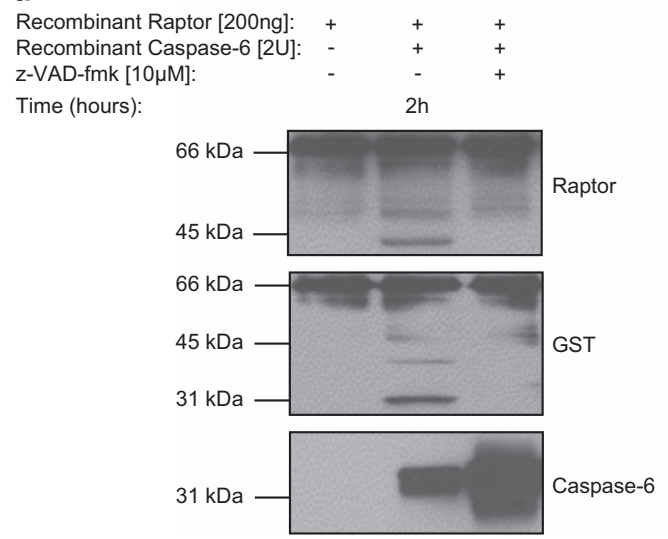

e

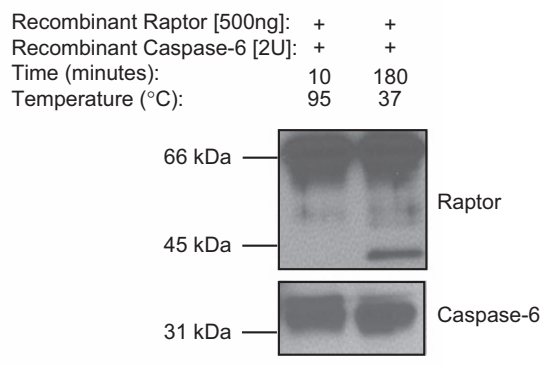

Figure 5. Cleavage of raptor at the C-term DDADD (amino acids 939-943) residue and at the N-term DEADLTD (amino acids 17-23) residue. (a) Cartoon of raptor and its putative C-term caspase-mediated cleavage residues (UniProtKB: Q8N122). The recombinant N-term raptor protein (amino acids 1-379) is represented by the arrow. Different N-term tags (HA or GST) were used according to the raptor constructs. (b) Jurkat T cells were transfected with GFP, WT, DDAAA or AVAAKA raptor and treated with STS for $2 \mathrm{~h}$. (c) Jurkat T cells were transfected with GFP, WT or DDAAA raptor and treated with FasL for $2 \mathrm{~h}$. (d) Recombinant N-term raptor was incubated with recombinant caspase-6 for $2 \mathrm{~h}$ in the presence (or in the absence) of z-VAD-fmk. (e) Recombinant raptor was incubated with recombinant caspase- 6 and directly inactivated at $95^{\circ} \mathrm{C}$ for $10 \mathrm{~min}$ or incubated for $3 \mathrm{~h}$ at $37^{\circ} \mathrm{C}$. The samples were analyzed by tandem MS.

the N-term sequence of raptor (amino acid 1-379) fused to the $\mathrm{N}$-terminus with GST (Figure 5a). Incubation of the $\mathrm{N}$-term recombinant raptor with recombinant caspase- 6 generated a cleavage of raptor from the $70 \mathrm{kDa}$ into a molecular species of $40 \mathrm{kDa}$, indicating the presence of a caspase-6-mediated cleavage site at the beginning of the raptor sequence, after the GST tag (Figure 5d).

Next, two samples were prepared to identify the raptor N-term cleavage site(s) by mass spectrometry (MS) (Figure 5e). A tryptic peptide with sequence LTDWNLPLAFMK was clearly detected, which resulted from cleavage after an aspartate residue in the sequence DEAD (amino-acid 20) (Supplementary Figure S2). In addition, another potential caspase-6-specific cleavage site (DEADLTD, amino-acid 23) was found next to the DEAD site. This potential cleavage site seemed less prone to be cleaved by caspase- 6 , as it appeared in much lower amounts as judged by spectral counts (Supplementary Figure S2). Moreover, recombinant caspase-3 or -7 were also able to process the $\mathrm{N}$-term recombinant raptor into a $41 \mathrm{kDa}$ fragment, similary to recombinant caspase-6 (Supplementary Figure S3).

Taken together, these data indicated that raptor could be cleaved in vitro by caspase- 6 (and by caspase- 3 and -7) after two $\mathrm{N}$-term aspartate residues localized next to each other as present in the DEADLTD sequence.

Raptor processing correlates with $\mathrm{mTORC} 1$ inhibition and cell death

As raptor has an important role as a scaffold protein within mTORC1, the processing of raptor could have a negative effect on mTORC 1 structure and activity. To assess whether the processing of raptor led to the inhibition of mTORC1 signaling, the downstream targets of mTORC1 were analyzed for phosphorylation, as well as the phosphorylation of mTOR at Ser2448 by an upstream activator, Akt. ${ }^{46,47}$ Incubation of Jurkat T cells with STS or FasL for 2, 4 and $6 \mathrm{~h}$ led to progressive cleavage of raptor, whereas phosphorylation levels of $\mathrm{mTOR}, 4 \mathrm{E}-\mathrm{BP} 1$ and $\mathrm{S} 6 \mathrm{~K}$ were all 
a

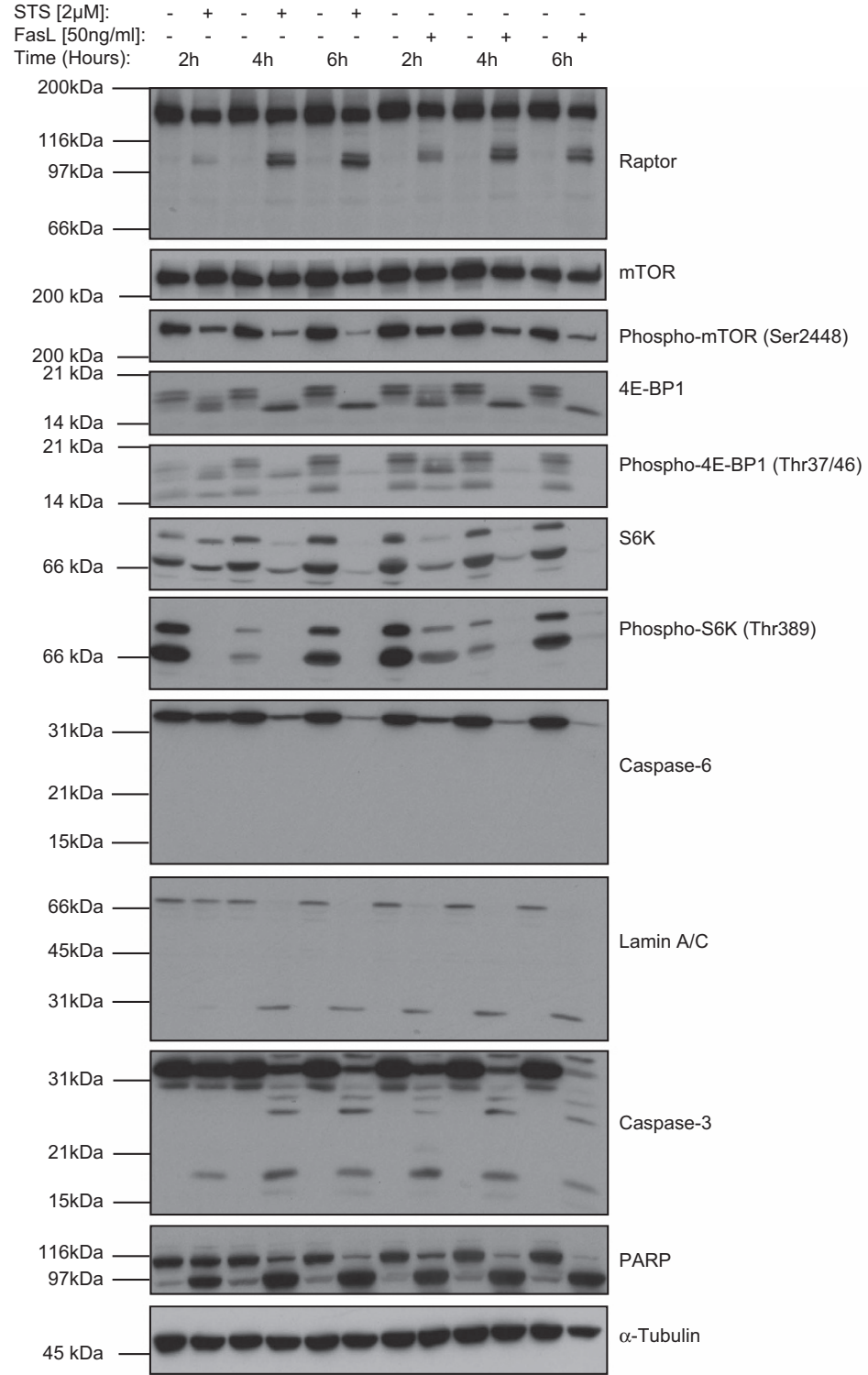

b Staurosporine $[2 \mu \mathrm{M}]: \quad-\quad+$ Total cell lysate IP: mTOR Time (hours): $4 \mathrm{~h}$

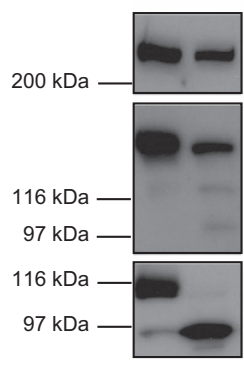

- +

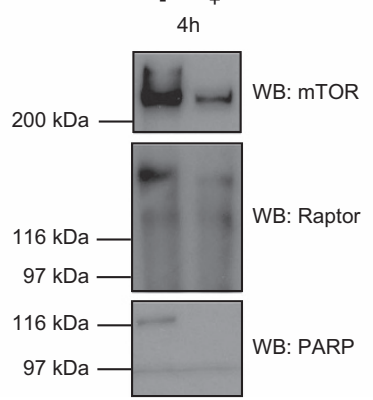

Cell death sensitivity

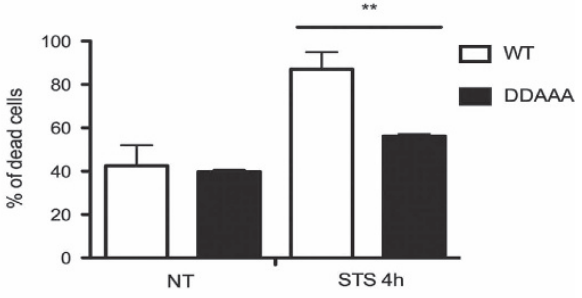

Figure 6. Inhibition of mTORC1 and cell death sensitivity caused by raptor processing and decrease of mTOR-raptor interaction. (a) Jurkat T cells were treated with STS or FasL for 2, 4 or $6 \mathrm{~h}$. Raptor processing, phosphorylation of mTORC1 substrates (S6K, 4E-BP1), caspase-3 and - 6 activations were analyzed. (b) Untreated or STS-treated Jurkat T-cell lysates were IP with an antibody raised against mTOR. Raptor-mTOR interaction, PARP and raptor cleavage were analyzed. (c) Jurkat T cells were transfected with WT or DDAAA raptor constructs and treated with STS for $4 \mathrm{~h}$. A live/dead staining was used to quantify the percentage of cell death by flow cytometry. The unpaired Student's $t$-test (Prism software) was used to calculate the significative difference. ${ }^{* *} P=0.0025$. Data are represented as mean \pm S.E.M.; $n=3$. 

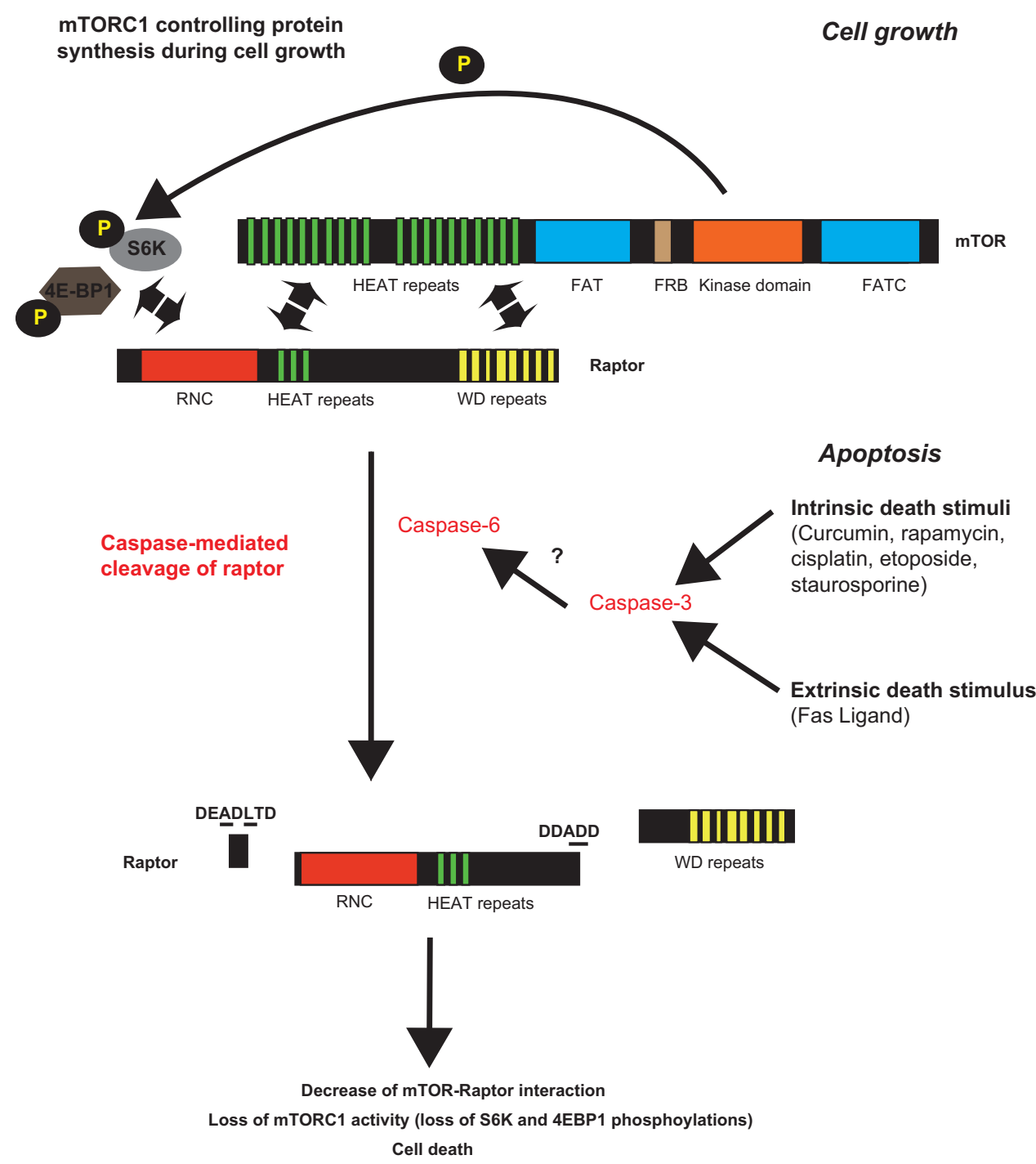

Figure 7. Model representing mTORC1 modulation from cell growth to apoptosis.

decreasing after incubation with STS or FasL (Figure 6a). As STS is a protein kinase inhibitor, a decrease in multiple phosphorylation events was expected. However, FasL has no direct effect on protein kinase activity and nevertheless, the same decrease of phosphorylation of mTOR substrates was observed, suggesting that the effect on their phosphorylation was linked to the processing of raptor. Thus, activation of caspase- 3 and -6 , as well as cleavage of their respective substrates (PARP, lamin $A / C$ ), correlated perfectly with cleavage of raptor and with loss of phosphorylation of 4E-BP1 and S6K.

Although raptor is essential for binding and recruiting mTOR substrates, ${ }^{15}$ several studies showed that treatment with curcumin or with high concentrations of rapamycin induced the weakening of the raptor-mTOR interaction, ${ }^{34,36}$ which could affect the mTORC1 activity. Figure $6 \mathrm{~b}$ showed by immunoprecipitation (IP) that mTOR was bound to raptor in the untreated sample, but the interaction was strongly reduced in the STS-treated sample and no processed band was observed at $100 \mathrm{kDa}$ after IP, suggesting that raptor cleavage weakens the mTOR-raptor interaction and that the cleaved raptor is probably released from the complex.

As the mutation of the C-term raptor cleavage site abolished raptor processing after apoptosis induction, and the interaction between raptor and mTOR was altered when raptor was cleaved, we hypothesized that the absence of raptor processing could lead to a difference in cellular survival under stress conditions. For this reason, we investigated the effect of overexpressing a cleavageresistant mutant of raptor (DDAAA) versus WT raptor on apoptosis induction (Figure $6 \mathrm{c}$ ). Apoptosis induction with STS had a strong effect on cells transfected with the raptor WT construct (almost $90 \%$ of dead cells), whereas cells transfected with cleavageresistant raptor (DDAAA) showed a significative reduction in STSinduced cell death (nearly 60\%). Thus, raptor cleavage had an important role in the apoptotic cascade, as the abolition of its processing induced resistance against cell death.

Taken together, these results suggested that raptor processing correlated with its dissociation from mTORC1, loss of phosphorylation of mTOR substrates and thus, inactivation of the mTORC1 during apoptosis.

\section{DISCUSSION}

In this study, we investigated the molecular mechanisms involved in the targeting of $\mathrm{mTORC} 1$ by anticancer drugs, as this complex is frequently hyperactivated in human cancers. Treatment of different lymphoma T- and B-cell lines with anticancer drugs like cisplatin, etoposide, rapamycin, curcumin and apoptosis inducers like STS and FasL led to the processing of the $150 \mathrm{kDa}$ raptor protein into a smaller fragment of $100 \mathrm{kDa}$. Interestingly, 
rapamycin is known as an allosteric inhibitor of $\mathrm{mTORC1}$, which, at low concentrations, binds to the intracellular protein FKBP12 to form a gain-of-function complex, inducing inhibition of mTORC1. Repression of $\mathrm{mTORC} 1$ by low dose of rapamycin will give rise to induction of autophagy, as mTORC1 normally blocks initiation of autophagy through Unc-51 like autophagy activating kinase 1 (ULK1) inhibition. Contrariwise, high doses (defined as $20 \mu \mathrm{M}$ ) of rapamycin were shown to induce apoptosis (cleavage of PARP) as well as mTOR-raptor dissociation and loss of phosphorylation of $4 \mathrm{E}-\mathrm{BP} 1{ }^{36,39}$ The precise mechanism of action of rapamycin (at high dose) has not been described but our results can explain the missing gap, as we showed that rapamycin (as well as other drugs) led to caspase activation (Supplementary Figures S4 and S5), which cleaved raptor, dislocated and therefore inhibited the mTORC1. In our hands, both high and low concentrations of rapamycin gave rise to processing of raptor and activation of caspases in different cell lines and with varying kinetics (Figure 1d and Supplementary Figure S5). In addition, drugs triggering either the intrinsic (cisplatin, etoposide, STS) or the extrinsic (FasL) apoptosis cascades induced raptor processing, which indicated that different cell death stimuli converged to raptor cleavage.

Here we identified caspase- 6 as a key protease involved in the cleavage of raptor at the $\mathrm{C}$-term and at the $\mathrm{N}$-term, but other caspases could have a redundant role, as some processing of raptor was still present in caspase- $6 \mathrm{KO}$ cells. This is coherent considering the importance of $\mathrm{mTORC} 1$ as a major regulator of cellular anabolic processes. Therefore, different caspases most likely act together to process raptor, inhibit the mTORC 1 and thus block cell growth.

The identification of caspase-mediated raptor cleavage sites revealed that the $\mathrm{C}$-term cleavage site was located between the HEAT repeats and the WD repeats, whereas the N-term cleavage site was situated at the beginning of raptor $\mathrm{N}$-term conserved (RNC) domain. The 3-dimensional (3D) structure of the mTORC1 has been resolved using cryo-electron microscopy and revealed the dimeric aspect of the complex. ${ }^{12,13}$ In fact, raptor is situated at the interface between two mTOR molecules and the overall structure of the complex is forming a circle-like shape. Based on this 3D structure, the C-terminus of raptor is situated in between two mTOR proteins, but the N-terminus of raptor is free and located at the outside of $\mathrm{mTORC} 1$, probably to access more easily mTOR substrates such as $4 \mathrm{E}-\mathrm{BP} 1$ and $\mathrm{S} 6 \mathrm{~K}$. We would expect that processing after the DDADD C-term cleavage site destabilizes the complex, as this site is situated at the point of contact with two mTOR proteins. The N-term DEADLTD raptor cleavage site could affect the binding of $4 \mathrm{E}-\mathrm{BP} 1$ and $\mathrm{S} 6 \mathrm{~K}$ to raptor and thus, reduce their phosphorylation. Furthermore, a previous study highlighted that mutagenesis in the RNC or in the WD repeats of raptor gave rise to a loss of the mTOR-raptor interaction. ${ }^{14}$ Thus, raptor cleavage, which removes a part of the RNC domain and the WD repeats, could abolish this interaction as well. This hypothesis was clearly supported by our experiments, which showed a correlation between raptor cleavage, decrease of raptor-mTOR binding and loss of phosphorylation of mTOR, S6K and 4E-BP1 (Figures 6a and b). Moreover, cleavage of raptor in its $\mathrm{C}$-term region could induce a loss of phosphorylation via the release of the cleaved raptor fragment from mTORC1. In this scenario, the processed portion of raptor (unbound and outside MTORC1) could compete with the remaining unprocessed raptor (bound and inside mTORC1) for mTOR substrates and thus, decrease the amount of phosphorylated S6K and 4E-BP1.

Interestingly, the cleavage of raptor had a strong effect at the cellular level, as the transfection of the cleavage-resistant raptor mutant (DDAAA) conferred resistance to cell death compared with transfection with WT raptor. This indicated that the processing of raptor was required during the apoptosis cascade to properly deactivate the mTORC1 function and stop cell growth. Collectively, our findings support a model (Figure 7) in which either intrinsic or extrinsic apoptosis pathways lead to activation of executioner caspases (caspase-3, -6 and -7 ), which cleave raptor at two specific cleavage sites (at least). These cleavage events give rise to a decrease in the raptor-mTOR interaction and the release of the cleaved raptor from the mTORC1. The MTORC1 is dislocated and inactivated (loss of mTOR substrates phosphorylation), which is crucial to execute the cell death cascade.

An important consequence of our findings is that the processing of raptor can now be used as a new marker of apoptosis and as a complementary indicator of mTORC1 inhibition. As phosphorylations are sometimes difficult to interpret, the cleavage of raptor is a novel precise indicator of mTORC1 inactivation, caspase activation and efficient triggering of the cell death cascade. Novel strategies are required to target the mTORC1, circumvent drug-resistance and stop cancer progression. Our study may also have direct applications for drug screening, as the cleavage of raptor can be used as a selecting marker for the identification of mTORC1-targeting drugs.

\section{MATERIALS AND METHODS}

Antibodies, reagents and drugs

Anti-raptor (cat. no. 2280), anti-mTOR (cat. no. 2983), anti-phospho-mTOR Ser2448 (cat. no. 5536), anti-4E-BP1 (cat. no. 9452), anti-phospho-4E-BP1 Thr37/46 (cat. no. 2855), anti-p70 S6K (cat. no. 9202), anti-phospho-S6K Thr389 (cat. no. 9234), anti-cleaved-caspase-7 (cat. no. 9491), anti-cleavedcaspase-6 (cat. no. 9761), anti-caspase-6 (cat. no. 9762), anti-caspase-3 (cat. no. 9662), anti-PARP (cat. no. 9542), anti-lamin A/C (cat. no. 2032) and antiIL-1 $\beta$ (cat. no. 12242) antibodies were purchased from Cell Signaling Technologies (Danvers, MA, USA). Anti-caspase-1 (cat. no. SC514) antibody was obtained from Santa Cruz Biotechnology (Dallas, TX, USA). Anti-atubulin (cat. no. T6074) and anti-HA Tag (cat. no. H3663) were ordered from Sigma (St. Louis, MO, USA).

Cisplatin (cat. no. ALX-400-040), etoposide (cat. no. BML-GR307-0100), rapamycin (cat. no. BML-A275-0005), STS (cat. no. ALX-380-014-M001) and Dec-RVKR-cmk (cat. no. ALX-260-022) were all ordered from Enzo Life Sciences (Farmingdale, NY, USA). Curcumin (cat. no. C1386) and E64D (cat. no. E3132) were purchased from Sigma. The irreversible, cell permeable broad-spectrum caspase inhibitor (z-VAD-fmk, cat. no. N-1510-0005) was obtained from Bachem (Bubendorf, Switzerland). Active recombinant caspases-1, -2, -3, -6, -7, -8, -9 (cat. no. BV-K232-2) were ordered from MBL (Woburn, MA, USA). Recombinant human $\mathrm{mTOR} /$ Raptor/mLST8 (cat. no. SRP0364) was purchased from Sigma. Recombinant N-terminus Raptor (cat. no. ab112419) was purchased from Abcam (Cambridge, UK). The recombinant FasL (Fc:FasL) was kindly provided by Professor Pascal Schneider. ${ }^{40}$ The sequencing grade modified trypsin (cat. no. V5111) was obtained from Promega (Dübendorf, Switzerland).

\section{Cells and cell culture conditions}

KBM-7 WT and caspase-6 deficient cells (cat. no. P01285E07) were purchased from Horizon-Genomics (Cambridge, UK). T and B lymphoma cell lines were cultured in RPMI-1640 (Gibco, Carlsbad, CA, USA) supplemented with $10 \% \mathrm{FCS}, 1 \%$ HEPES and $1 \%$ penicillin $(10000 \mathrm{IU} / \mathrm{ml})$ and streptomycin $(10000 \mu \mathrm{g} / \mathrm{ml})$. KBM-7 cell lines were maintained in IMDM (Gibco) supplemented with 10\% FCS, 1\% HEPES and 1\% penicillin $(10000 \mathrm{IU} / \mathrm{ml})$ and streptomycin $(10000 \mu \mathrm{g} / \mathrm{ml})$. Cells were cultured at $37^{\circ} \mathrm{C}$ with $5 \% \mathrm{CO}_{2}$ and splited every 2 days.

\section{Drug treatments and western blot}

Cells were seeded in 12-well plates at $10^{6}$ cells $/ \mathrm{ml}$ in $1 \mathrm{ml}$ in culture medium and drugs were added for various period of time. Cells were recovered, spun down for $5 \mathrm{~min}$ at $500 \times g$ and pellets were resuspended in 1x RIPA buffer (Bio Basic Inc., Markham, Canada)/cat. no. RB4478) containing protease/phosphatase inhibitors (Cell Signaling Technologies/ cat. no. 5872S) and kept on ice for lysis for $20 \mathrm{~min}$. Cleared cell lysates were obtained after 5 -min centrifugation at $14000 \times g$. Cell lysates were dosed for protein concentration using a BCA protein assay kit (Thermo Scientific, Zug, Switzerland)/cat. no. 23225). Thirty microgram of protein was loaded on $8 \%$ or $12 \%$ SDS-PAGE. Standard western blot procedure was followed. 


\section{In vitro caspase reaction}

Jurkat T cells $\left(5 \times 10^{5}\right.$ cells per condition) were lysed in $10 \mu \mathrm{l}$ of $1 \times$ RIPA buffer without protease/phosphatase inhibitors. Cell lysate was incubated in $30 \mu \mathrm{l}$ of $1 \mathrm{x}$ caspase reaction buffer $(50 \mathrm{mM}$ HEPES, $\mathrm{pH} 7.2,50 \mathrm{mM} \mathrm{NaCl}$, $0.1 \%$ CHAPS, $10 \mathrm{mM}$ EDTA, $5 \%$ glycerol and $10 \mathrm{mM}$ DTT) with two units of various recombinant caspases. The reaction was performed at $37^{\circ} \mathrm{C}$ for 2 to $4 \mathrm{~h}$. Reactions were stopped by the addition of sample buffer and boiling of the sample for $5 \mathrm{~min}$ at $95^{\circ} \mathrm{C}$. For the in vitro caspase reactions performed on recombinant $\mathrm{mTOR} /$ Raptor $/ \mathrm{mLST}$ or on recombinant $\mathrm{N}$-terminus Raptor, $1-2 \mu \mathrm{g}$ of recombinant protein were added directly into the caspase reaction buffer in the presence of recombinant caspases.

\section{Caspase-1 activation in BMDMø}

BMDMø were generated from C57BL/6 mice using standard protocol. ${ }^{41}$ BMDM $\varnothing$ were plated in 48 -well plates at $2.5 \times 10^{5}$ cells per well. The priming step was performed with ultrapure LPS (Labforce, Muttenz, Switzerland) $(100 \mathrm{ng} / \mathrm{ml})$ for $3 \mathrm{~h}$. Following priming, the inflammasome was activated with $5 \mu \mathrm{M}$ Nigericin (Sigma) or $5 \mathrm{mM}$ ATP for $1 \mathrm{~h}$. Supernatants were collected and proteins were precipitated using methanol-chloroform protocol. Cell lysates were collected using 1x RIPA buffer.

\section{MS analysis}

Recombinant N-terminus raptor (500 ng) was incubated with two units (U) of recombinant caspase- 6 and boiled for $10 \mathrm{~min}$ at $95^{\circ} \mathrm{C}$ or incubated at $37^{\circ} \mathrm{C}$ for $3 \mathrm{~h}$. Samples were run on a $10 \%$ SDS-PAGE and stained overnight with colloidal Coomassie blue and then destained. Interesting bands were cut and partially digested with trypsin (1 h 30-min incubation) into peptides, which were then analyzed by nano-HPLC and high-resolution tandem MS (nanoLC-MS/MS). The database searching software MASCOT (Boston, MA, USA) was used to match the generated spectra to known protein sequences with a mass tolerance of 10 p.p.m. for the precursor peptide mass and 0.5 Da for tandem MS fragments. Cleavage specificity for peptide matching was semi-tryptic (only one cut C-term to Lys and Arg was required)

\section{Raptor vectors}

HA WT raptor plasmid was a gift from David Sabatini (Addgene plasmid \# 8513, Cambridge, MA, USA). ${ }^{14}$ Raptor mutants (DDAAA/AVAAKA) were generated by Genscript (Piscataway, NJ, USA).

\section{Transfections}

Jurkat T cells were transfected using Amaxa Cell line Nucleofector Kit V (Lonza, Visp, Switzerland/cat. no, VCA-1003) following the manufacturer's protocol. After overnight incubation at $37{ }^{\circ} \mathrm{C}$ with $5 \% \mathrm{CO}_{2}$, fresh RPMI was added on the cells for another 24-h incubation. Fourty-eight hours post transfections, cell death was induced either with FasL $(50 \mathrm{ng} / \mathrm{ml})$ or STS $(2 \mu \mathrm{M})$ for $2-4 \mathrm{~h}$.

\section{Immunoprecipitation}

Six million Jurkat T cells were treated with $2 \mu \mathrm{M}$ of STS for $6 \mathrm{~h}$ or left untreated. Cells were washed once in PBS and resuspended in a lysis buffer containing $20 \mathrm{mM}$ Tris (pH 7.5), $150 \mathrm{mM} \mathrm{NaCl}, 1 \mathrm{mM}$ EDTA, 0.3\% CHAPS and $1 / 100$ protease/phosphatease inhibitor cocktail (Cell Signaling Technologies, cat. no. 5872S). Cells were left 20 min on ice and centrifuged at $14000 \times g$ for $5 \mathrm{~min}$ to obtain cleared cell lysates. Cell lysates were incubated with gentle rocking with anti-mTOR antibody (Cell Signaling Technologies, cat. no. 2983, dilution 1/50) for an overnight incubation at $4{ }^{\circ} \mathrm{C}$. The next day, protein A/G PLUS-agarose beads (Santa Cruz Biotechnology, cat. no. sc-2003) was added to the cell lysate/antibody mix for an additional 3-h incubation with gentle rocking at $4{ }^{\circ} \mathrm{C}$. Then beads were washed with lysis buffer five times, SDS sample buffer was added, samples were heated for $5 \mathrm{~min}$ at $95^{\circ} \mathrm{C}$ and loaded on a $6 \%$ SDSPAGE for wertern blot analysis.

\section{Cell death sensitivity test}

Fourty-eight hours post transfection, cells were treated with STS $(2 \mu \mathrm{M})$ for $4 \mathrm{~h}$ or left untreated. Then cells were stained using the LIVE/DEAD fixable far red dead cell stain kit (cat. no. L10120, Invitrogen, Waltham, MA, USA) following the manufacturer's protocol. Cell death was quantified by flow cytometry (Accuri C6 flow cytometer, Ann Arbor, MI, USA). Statistical significance of differences was calculated using unpaired Student's $t$-test with the Prism software (Irvine, CA, USA).

\section{ACKNOWLEDGEMENTS}

We thank Professor Fabio Martinon for providing aliquots of LPS, ATP, nigericin and IL-1 $\beta$ and caspase-1 antibodies. We thank Professor Pascal Schneider for providing the recombinant Fc-FasL. We also thank Megane Bernard and Julien Bourquin for their technical help. This work was funded by the grants FNRS N ${ }^{\circ} 3100 A 0-116665 / 1$ and IZ70Z0-131421 2 2 PDAMP3_127171 (MT-M and NF) and the association Institute for Arthritis Research (aIAR).

\section{AUTHOR CONTRIBUTIONS}

Conceptualization: RM, MT-M and NF; Methodology: RM; Investigation, RM, CD, ROE and MQ; Resources: MT-M; Writing - original draft: RM, NF and MT-M; Writing - review and editing: RM, NF and MT-M; Supervision: NF; Project administration: NF; Funding acquisition: MT-M and NF.

\section{COMPETING INTERESTS}

The authors declare no conflict of interest.

\section{REFERENCES}

1 Laplante M, Sabatini DM. mTOR signaling in growth control and disease. Cell 2012; 149: 274-293.

2 Loewith R, Jacinto E, Wullschleger S, Lorberg A, Crespo JL, Bonenfant D et al. Two TOR complexes, only one of which is rapamycin sensitive, have distinct roles in cell growth control. Mol Cell 2002; 10: 457-468.

3 Peterson TR, Laplante M, Thoreen CC, Sancak Y, Kang SA, Kuehl WM et al. DEPTOR is an mTOR inhibitor frequently overexpressed in multiple myeloma cells and required for their survival. Cell 2009; 137: 873-886.

$4 \mathrm{Kim}$ DH, Sarbassov DD, Ali SM, Latek RR, Guntur KV, Erdjument-Bromage $\mathrm{H}$ et al. GbetaL, a positive regulator of the rapamycin-sensitive pathway required for the nutrient-sensitive interaction between raptor and mTOR. Mol Cell 2003; 11: 895-904.

5 Kaizuka T, Hara T, Oshiro N, Kikkawa U, Yonezawa K, Takehana K et al. Tti1 and Tel2 are critical factors in mammalian target of rapamycin complex assembly. J Biol Chem 2010; 285: 20109-20116.

6 Hara K, Maruki Y, Long X, Yoshino K, Oshiro N, Hidayat S et al. Raptor, a binding partner of target of rapamycin (TOR), mediates TOR action. Cell 2002; 110: 177-189.

7 Sancak Y, Thoreen CC, Peterson TR, Peterson TR, Lindquist RA, Kang SA et al. PRAS40 is an insulin-regulated inhibitor of the mTORC1 protein kinase. Mol Cell 2007; 25: 903-915.

8 Sarbassov DD, Ali SM, Kim DH, Guertin DA, Latek RR, Erdjument-Bromage $\mathrm{H}$ et al. Rictor, a novel binding partner of mTOR, defines a rapamycin-insensitive and raptor-independent pathway that regulates the cytoskeleton. Curr Biol 2004; 14: 1296-1302.

9 Jacinto E, Loewith R, Schmidt A, Lin S, Rüegg MA, Hall A et al. Mammalian TOR complex 2 controls the actin cytoskeleton and is rapamycin insensitive. Nat Cell Biol 2004; 6: 1122-1128.

10 Jacinto E, Facchinetti V, Liu D, Soto N, Wei S, Jung SY et al. SIN1/MIP1 maintains rictor-mTOR complex integrity and regulates Akt phosphorylation and substrate specificity. Cell 2006; 127: 125-137.

11 Pearce LR, Sommer EM, Sakamoto K, Wullschleger S, Alessi DR. Protor-1 is required for efficient $m$ TORC2-mediated activation of SGK1 in the kidney. Biochem J 2011; 436: 169-179.

12 Aylett $\mathrm{CH}$, Sauer E, Imseng S, Boehringer D, Hall MN, Ban N et al. Architecture of human mTOR complex 1. Science 2016; 351: 48-52.

13 Yip CK, Murata K, Walz T, Sabatini DM, Kang SA. Structure of the human mTOR complex $\mathrm{I}$ and its implications for rapamycin inhibition. Mol Cell 2010; 38: 768-774.

14 Kim DH, Sarbassov DD, Ali SM, King JE, Latek RR, Erdjument-Bromage $\mathrm{H}$ et al. mTOR interacts with raptor to form a nutrient-sensitive complex that signals to the cell growth machinery. Cell 2002; 110: 163-175.

15 Nojima H, Tokunaga C, Eguchi S, Oshiro N, Hidayat S, Yoshino K et al. The mammalian target of rapamycin (mTOR) partner, raptor, binds the mTOR substrates p70 S6 kinase and 4E-BP1 through their TOR signaling (TOS) motif. J Biol Chem 2003; 278: 15461-15464. 
16 Gingras AC, Gygi SP, Raught B, Polakiewicz RD, Abraham RT, Hoekstra MF et al. Regulation of 4E-BP1 phosphorylation: a novel two-step mechanism. Genes Dev 1999; 13: 1422-1437.

17 Gingras AC, Raught B, Gygi SP, Niedzwiecka A, Miron M, Burley SK et al. Hierarchical phosphorylation of the translation inhibitor 4E-BP1. Genes Dev 2001; 15: 2852-2864.

18 Magnuson B, Ekim B, Fingar DC. Regulation and function of ribosomal protein S6 kinase (S6K) within mTOR signalling networks. Biochem J 2012; 441: 1-21.

19 Tavares MR, Pavan IC, Amaral CL, Meneguello L, Luchessi AD, Simabuco FM. The S6K protein family in health and disease. Life Sci 2015; 131: 1-10.

20 Menon S, Manning BD. Common corruption of the mTOR signaling network in human tumors. Oncogene 2008; 27: S43-S51.

21 Grabiner BC, Nardi V, Birsoy K, Possemato R, Shen K, Sinha S et al. A diverse array of cancer-associated MTOR mutations are hyperactivating and can predict rapamycin sensitivity. Cancer Discov 2014; 4: 554-563.

22 Chresta CM, Davies BR, Hickson I, Harding T, Cosulich S, Critchlow SE et al. AZD8055 is a potent, selective, and orally bioavailable ATP-competitive mammalian target of rapamycin kinase inhibitor with in vitro and in vivo antitumor activity. Cancer Res 2010; 70: 288-298.

23 Vilar E, Perez-Garcia J, Tabernero J. Pushing the envelope in the mTOR pathway: the second generation of inhibitors. Mol Cancer Ther 2011; 10: 395-403.

24 Feldman ME, Apsel B, Uotila A, Loewith R, Knight ZA, Ruggero D et al. Active-site inhibitors of mTOR target rapamycin-resistant outputs of mTORC1 and mTORC2. PLoS Biol 2009; 7: e38.

25 Garcia-Martinez JM, Moran J, Clarke RG, Gray A, Cosulich SC, Chresta CM et al. Ku-0063794 is a specific inhibitor of the mammalian target of rapamycin (mTOR). Biochem J 2009; 421: 29-42.

26 Thoreen CC, Kang SA, Chang JW, Liu Q, Zhang J, Gao Y et al. An ATP-competitive mammalian target of rapamycin inhibitor reveals rapamycin-resistant functions of mTORC1. J Biol Chem 2009; 284: 8023-8032.

27 Yu K, Toral-Barza L, Shi C, Zhang WG, Lucas J, Shor B et al. Biochemical, cellular, and in vivo activity of novel ATP-competitive and selective inhibitors of the mammalian target of rapamycin. Cancer Res 2009; 69: 6232-6240.

28 Tsukasaki K, Utsunomiya A, Fukuda H, Shibata T, Fukushima T, Takatsuka Y et al. VCAP-AMP-VECP compared with biweekly CHOP for adult T-cell leukemia-lymphoma: Japan Clinical Oncology Group Study JCOG9801. J Clin Oncol 2007; 25: 5458-5464.

29 Sinha R, Shenoy PJ, King N, Lechowicz MJ, Bumpers K, Hutcherson D et al. Vinorelbine, paclitaxel, etoposide, cisplatin, and cytarabine (VTEPA) is an effective second salvage therapy for relapsed/refractory Hodgkin lymphoma. Clin Lymphoma Myeloma Leuk 2013; 13: 657-663.

30 Tee AR, Proud CG. DNA-damaging agents cause inactivation of translational regulators linked to mTOR signalling. Oncogene 2000; 19: 3021-3031.

31 Itamochi H, Oishi T, Shimada M, Sato S, Uegaki K, Naniwa J et al. Inhibiting the mTOR pathway synergistically enhances cytotoxicity in ovarian cancer cells induced by etoposide through upregulation of c-Jun. Clin Cancer Res 2011; 17: 4742-4750.

32 Mabuchi S, Altomare DA, Cheung M, Zhang L, Poulikakos PI, Hensley HH et al. RAD001 inhibits human ovarian cancer cell proliferation, enhances cisplatininduced apoptosis, and prolongs survival in an ovarian cancer model. Clin Cancer Res 2007; 13: 4261-4270.
33 Guo LD, Chen XJ, Hu YH, Yu ZJ, Wang D, Liu JZ. Curcumin inhibits proliferation and induces apoptosis of human colorectal cancer cells by activating the mitochondria apoptotic pathway. Phytother Res 2013; 27: 422-430.

34 Beevers CS, Chen L, Liu L, Luo Y, Webster NJ, Huang S. Curcumin disrupts the Mammalian target of rapamycin-raptor complex. Cancer Res 2009; 69: 1000-1008.

35 Johnson SM, Gulhati P, Arrieta I, Wang X, Uchida T, Gao T et al. Curcumin inhibits proliferation of colorectal carcinoma by modulating Akt/mTOR signaling. Anticancer Res 2009; 29: 3185-3190.

36 Yellen P, Saqcena M, Salloum D, Feng J, Preda A, Xu L et al. High-dose rapamycin induces apoptosis in human cancer cells by dissociating mTOR complex 1 and suppressing phosphorylation of 4E-BP1. Cell Cycle 2011; 10: 3948-3956.

37 Wang P, Song JH, Song DK, Zhang J, Hao C. Role of death receptor and mitochondrial pathways in conventional chemotherapy drug induction of apoptosis. Cell Signal 2006; 18: 1528-1535.

38 Inoue S, Browne G, Melino G, Cohen GM. Ordering of caspases in cells undergoing apoptosis by the intrinsic pathway. Cell Death Differ 2009; 16: 1053-1061.

39 Saqcena M, Patel D, Menon D, Mukhopadhyay S, Foster DA. Apoptotic effects of highdose rapamycin occur in S-phase of the cell cycle. Cell Cycle 2015; 14: 2285-2292.

40 Holler N, Tardivel A, Kovacsovics-Bankowski M, Hertig S, Gaide O, Martinon F et al. Two adjacent trimeric Fas ligands are required for Fas signaling and formation of a death-inducing signaling complex. Mol Cell Biol 2003; 23: 1428-1440.

41 Gross O. Measuring the inflammasome. Methods Mol Biol 2012; 844: 199-222.

42 Walsh JG, Cullen SP, Sheridan C, Luthi AU, Gerner C, Martin SJ. Executioner caspase-3 and caspase-7 are functionally distinct proteases. Proc Natl Acad Sci USA 2008; 105: 12815-12819.

43 Ruchaud S, Korfali N, Villa P, Kottke TJ, Dingwall C, Kaufmann SH et al. Caspase-6 gene disruption reveals a requirement for lamin A cleavage in apoptotic chromatin condensation. EMBO J 2002; 21: 1967-1977.

44 Takahashi A, Alnemri ES, Lazebnik YA, Fernandes-Alnemri T, Litwack G, Moir RD et al. Cleavage of lamin A by Mch2 alpha but not CPP32: multiple interleukin 1 beta-converting enzyme-related proteases with distinct substrate recognition properties are active in apoptosis. Proc Natl Acad Sci USA 1996; 93: 8395-8400.

45 Schembri L, Dalibart R, Tomasello F, Legembre P, Ichas F, De Giorgi F. The HA tag is cleaved and loses immunoreactivity during apoptosis. Nat Methods 2007; 4: 107-108.

46 Sekulic A, Hudson CC, Homme JL, Yin P, Otterness DM, Karnitz LM et al. A direct linkage between the phosphoinositide 3-kinase-AKT signaling pathway and the mammalian target of rapamycin in mitogen-stimulated and transformed cells. Cancer Res 2000; 60: 3504-3513.

47 Reynolds THt, Bodine SC, Lawrence JC Jr. Control of Ser2448 phosphorylation in the mammalian target of rapamycin by insulin and skeletal muscle load. J Biol Chem 2002; 277: 17657-17662.

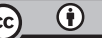

This work is licensed under a Creative Commons Attribution 4.0 nternational License. The images or other third party material in this article are included in the article's Creative Commons license, unless indicated otherwise in the credit line; if the material is not included under the Creative Commons license, users will need to obtain permission from the license holder to reproduce the material. To view a copy of this license, visit http://creativecommons.org/licenses/ by/4.0/

Supplemental Information accompanies the paper on the Cell Death and Discovery website (http://www.nature.com/cddiscovery) 